\title{
Falta um pacto na Saúde: elementos para a construção de um Pacto Ético-Político entre gestores e trabalhadores do SUS
}

Lack of a Covenant in Health: elements for building a Political-Ethical Pact between managers and workers in the SUS

Geovani Gurgel Aciole1

' Doutor em Saúde Coletiva pela Faculdade de Ciências Médicas da Universidade Estadual de Campinas (FCM/Unicamp) Campinas (SP), Brasil. Professor Adjunto do Departamento de Medicina da Universidade Federal de São Carlos (UFSCar) - São Carlos (SP), Brasil.

giovanni@ufscar.br
RESUMO Este ensaio considera o contexto da dinâmica social brasileira como desafio para as relações entre a gestão do sistema de saúde e o trabalho em saúde. Além dos pactos recentemente firmados entre os entes governamentais, reconhece a necessidade imperativa de um pacto ético/político entre gestores e trabalhadores. Nesse pacto, a gestão do sistema deve assumir a perspectiva cotidiana da produção do cuidado e nela reconhecer o protagonismo do ator essencial que são os trabalhadores de saúde. Diante da ausência de um pacto ético-político entre gestores e trabalhadores, apresenta uma proposta para sua construção, como contribuição à consolidação do Sistema Único de Saúde.

PALAVRAS CHAVE: Atenção à saúde; Recursos humanos; Gestão de pessoal; Sistema Único de Saúde; Saúde pública.

\begin{abstract}
This paper considers the context of brazilian social dynamics as a challenge for relations between the management of the health system and health work. In addition to the recently signed agreements between governmental entities, the study recognizes the imperative need for an ethical political pact between managers and workers. In this pact, the management system should take the daily perspective of care production and recognize the role of the essential actor who is the health worker. Given the absence of an ethical-political pact between managers and workers, presents a proposal for its build-up as a contribution to the consolidation of the Unified Health System.
\end{abstract}

KEYWORDS: Health care, human resources, personnel management; Unified Health System; Public Health. 


\section{Introdução}

Apesar de todas as dificuldades, dos desafios e problemas a enfrentar, o SUS tem se consolidado como uma política social efetiva para milhões de brasileiros. Assim é que podemos registrar a existência de uma rede de serviços composta por seis mil estabelecimentos hospitalares, com mais de 44 mil leitos disponíveis e cerca de sessenta e três mil unidades ambulatoriais. A produção anual dessa rede tem apresentado ritmo crescente $\mathrm{e}$ atingiu a marca anual de, aproximadamente, doze milhôes de internaçôes; um bilhão de procedimentos de atenção básica; cento e cinquenta milhóes de consultas médicas etc. Seu desempenho na área de transplantes faz do Brasil o segundo país no mundo nesse tipo de procedimento; reconhecido internacionalmente pelo seu desempenho na atençấo à área de DST/AIDS, garantindo atendimento universal aos portadores desses agravos; além de ser modelo pelos altos índices de cobertura vacinal e pelo atendimento relativo à atenção básica.

A peculiaridade do arranjo federativo brasileiro, estabelecido pela Constituição Federal de 1988, por exemplo, em que tanto estados quanto municípios constituem-se em entes federados, sem relação hierárquica, tornou complexa a construção de um sistema nacional de saúde, fundado em princípios de unicidade, universalidade e integralidade da atenção, e na diretriz de descentralização com comando único em cada nível de governo. Complexidade evidenciada pela problemática da organização do sistema, do desigual acesso da população às açôes de saúde, da marcante heterogeneidade entre estados e, mais ainda, entre municípios, com as consequências apontadas em torno do reconhecimento e da superação dos determinantes sociais da saúde nos marcos conceituais e concretos da desigualdade (ALMEIDA FILHO, 2010). A esse conjunto de desafios se acrescentam as dificuldades de tornar o espaço territorial/populacional e a área de abrangência político-administrativa de um município correspondentes a uma rede regionalizada e resolutiva de serviços com todos os níveis de complexidade.

Ao longo dos últimos anos, começou a ser disseminada a ideia de que a consolidaçáo do SUS exige a consideração de variáveis técnico-operacionais, territoriais, populacionais e assistenciais próprias para a conformação de redes regionalizadas e resolutivas de serviços; paralelamente e sem prejuízo do debate das questôes de natureza político-administrativa referentes à divisão de atribuiçóes entre a União, os estados e os municípios (ACIOLE, 2011; SANTOS; ANDRADE, 2008a; SANTOS; ANDRADE, 2008b; SILVA; MAGALHĀES JUNIOR, 2008). O desafio técnicopolítico de compatibilização de todas essas diretrizes já estava previsto no texto constitucional de 1988, que, em seu artigo 198, afirmava que as açóes e serviços públicos deveriam integrar uma rede regionalizada e hierarquizada, constituindo um sistema único, organizado de acordo com as diretrizes de descentralização, comando único, participação popular etc. Segundo a Lei 8.080/90, o controle e a avaliação das açôes e dos serviços de saúde são de competência comum dos gestores federal, estadual e municipal, cabendo a cada um a definição de suas instâncias e dos mecanismos próprios de atuação no seu âmbito políticoadministrativo. A referida lei procura, ainda, definir competências específicas de controle e avaliação para cada gestor, considerando o papel diferenciado que cada esfera assume no SUS.

É importante destacar que o aprofundamento do processo de regionalização só é possível em face dos avanços decorrentes do intenso processo prévio de descentralização, com ênfase na municipalização, induzido desde as primeiras Normas Operacionais Básicas do SUS 01/93 e 01/96 (SILVA; EGYDIO; SOUZA, 1999). Fato que possibilitou a emergência dos gestores municipais como atores políticos e afirmou a sua responsabilidade sanitária em um processo visível de descentralização administrativa no setor saúde. Em contrapartida, como apontam Levcovitz, Lima e Machado (2001), o nível federal ampliou seu papel indutor e regulador com mecanismos de transferência de recursos via açóes e programas assistenciais; a esfera estadual assumiu funções de coordenação e referência intermunicipal, mas segue tendo uma presença mais fragmentária. Ou seja, para aqueles autores, o desafio de implantação de um sistema nacional de saúde continua sendo pensar o funcionamento de um sistema 
federativo em um modelo de gestão financeira e tributária ainda bastante centralizado.

A experiência acumulada com o processo de descentralização trouxe, contudo, novos elementos para o amadurecimento da reflexão sobre as especificidades do papel de cada esfera de governo no Sistema Único de Saúde. O importante avanço da descentralização nos últimos anos requer, além disso, a ampliação do escopo da função de controle e avaliação no âmbito dos estados e, particularmente, dos municípios, de forma a superar o enfoque de avaliação de resultados, isto é, o transitar das atividades tradicionais de vistoria e controle de faturamento dos prestadores do sistema de saúde para a mensuração da qualidade do atendimento às necessidades de saúde dos usuários.

Os pressupostos políticos do momento atual indicam que, para o aprofundamento do processo de descentralização, deve-se ampliar a ênfase na regionalização e no aumento da equidade, buscando a organização de sistemas de saúde funcionais em todos os níveis de atenção, não necessariamente confinados aos territórios municipais e, portanto, sob responsabilidade coordenadora dos gestores estaduais. Além da lógica políticoadministrativa de delimitação dos sistemas de saúde, que assegura a indivisibilidade dos territórios municipais e estaduais no planejamento da rede e a autonomia dos entes governamentais na gestão, é fundamental considerar, para a definição do papel de cada nível de governo no sistema funcional, as noçóes de territorialidade na identificação de prioridades de intervenção e de organização de redes de assistência regionalizadas e resolutivas, além das capacidades técnico-operacionais necessárias ao exercício das funções de alocação de recursos, programação físico-financeira, regulação do acesso, contratação de prestadores de serviço, controle e avaliação.

Especialmente depois da experiência políticoinstitucional de gestão do trabalho e da educação na Saúde, realizada pelo Ministério da Saúde, a partir de 2003, a construção de equipes de trabalho singulares, cooperativas, autônomas e instrumentalizadas para atuar e intervir no quadrilátero da saúde (educação, gestão, modelo assistencial e controle social) se tornou elemento constituinte desse conjunto de açóes estruturantes
(CECCIN; FEUERWERKER, 2004a) e tem alimentado, inclusive, um conjunto de reflexôes em torno do processo de formação profissional para o SUS (CECCIN; FEUERWERKER, 2004b).

Pautados por esse cenário, os gestores das três esferas do SUS firmaram, em 2006, um compromisso público e institucional de construção do Pacto pela Saúde, de revisão anual, respeitando os princípios constitucionais do SUS e as necessidades de saúde da população, com implicação nos três eixos ordenadores: Pacto pela Vida, Pacto em Defesa do SUS e Pacto de Gestão do SUS (BRASIL, 2006). O Pacto pela Vida se constitui de um conjunto de compromissos ético-políticos derivados das situações epidemiológica e sanitária do país, consideradas suas disparidades regionais; e significa uma priorização de ações focadas em resultados e com a explicitação dos compromissos orçamentários e financeiros para sua execução pelas três esferas de governo.

As prioridades firmadas para 2006 foram, entre outras: implantar a política nacional de atenção à saúde do idoso; reduzir a mortalidade por câncer de colo de útero e de mama; reduzir a mortalidade materna, neonatal e infantil por diarreias e pneumonias; fortalecer a capacidade do sistema de responder às doenças endêmicas e emergentes, com ênfase na dengue, malária, hanseníase, tuberculose e influenza; elaborar e implantar a política nacional de promoção da saúde, internalizando, principalmente, hábitos saudáveis de atividade física e redução do tabagismo; e consolidar e qualificar a estratégia da saúde da família como modelo de atenção básica e como ordenadora das redes de atenção à saúde do SUS.

O Pacto em Defesa do SUS estabelece a ação organizada e concreta dos três níveis de governo para reforçá-lo como política pública de Estado, defendendo vigorosamente os princípios que a norteiam. Como prioridades apontadas em 2006, mencionamos: implementar um projeto de mobilização social que internalize nos corações e mentes a saúde como direito de cidadania e dever do Estado, e o SUS como política garantidora universal desse direito; alcançar a regulamentação da Emenda 29, que estabelece a política de financiamento do sistema; garantir o incremento dos recursos orçamentários/financeiros em todos os níveis 
de governo; e aprovar o orçamento do SUS, com participação de todas as esferas e explicitação de compromissos de cada uma delas.

O Pacto de Gestão do SUS estabelece as responsabilidades de cada esfera de governo, visando a diminuir e até eliminar as competências concorrentes, deixando mais clara a tarefa de cada governo para uma gestáo compartilhada e solidária do Sistema de Saúde. Neste sentido, o pacto reafirma a importância da participação e do controle social, e explicita as diretrizes para o financiamento tripartite: busca critérios para alocação equitativa de recursos, reforça os mecanismos de transferência de recursos interesferas, integra o fundo federal e estabelece relaçóes contratuais entre os três níveis de governo.

Como prioridades, o Pacto estabelece o compromisso com a inequívoca definição da responsabilidade sanitária de cada esfera de governo e pontua as diretrizes de gestão com ênfase na descentralização, na regionalização, no financiamento compartilhado, na programação pactuada e integrada, na participação e no controle social, no planejamento integrado e na gestão do trabalho e da educação na saúde, mas ainda teremos que aguardar o tempo histórico necessário para que os efeitos de tal agenda política sejam efetivamente sentidos. Até porque, em que pese a agenda de compromissos firmada pelos Pactos, a implantação efetiva de um sistema com essa ambição e complexidade exige uma organização que enfrente um conjunto crescente de dificuldades determinadas pela resistência dos interesses contrários a essa proposta. No momento atual, a dinâmica políticoadministrativa do SUS é afetada por questōes contextuais, como as decorrentes da política econômica federal, e seus âmbitos administrativo e previdenciário, ao lado das consequências da redistribuição de encargos e recursos nas três esferas de governo (DAIN, 2001), pela centralidade tributária, e mesmo pela tendência à flexibilização das relaçóes de trabalho resultante do processo de globalização econômica e social, com os reflexos considerados nas políticas e nos avanços de seguridade social (FLEURY; LOBATO, 2009; ACIOLE, 2006).

A proposta de pactos políticos é uma experiência fortemente incrustada na história institucional e política nacional, remontando à estruturação do Estado brasileiro desde as primeiras décadas do século XIX, que ganha inflexões nítidas nas últimas décadas do século $\mathrm{XX}$, com os contornos sociais que assume. Os pactos na saúde revelam, assim, forte vinculação com dimensões políticas e sociais. Esse seu caráter se revela essencial para a efetivação de políticas de Estado, ao garantir legitimidade para os atores institucionais e ao potencializar efetividade e governabilidade para as políticas públicas setoriais. A pactuação, portanto, não deve ser vista como marco acabado e exitoso de um acordo entre pares. Ao contrário, representa um processo de negociação permanente em busca da superação de conflitos intergovernamentais, e elo de construção de uma responsabilização solidária que, por meio de metas, indicadores e açóes bem definidas, constitua uma forma indutora de accountability e transparência, capaz de favorecer a democratização dos espaços institucionais de governo e o controle social (GUERREIRO; BLANCO, 2011). Nesse contexto, além disso, os serviços públicos atravessam uma fase de transição e de rearranjos funcionais e organizacionais, em que se colocam o debate de soluçóes entre as organizações sociais (OS) (MERHY, 1999) e/ou as fundações estatais (BRASIL, 2007).

Parece-nos, pois, de fundamental importância que a política de gestão do trabalho para a saúde seja destacada, e que nela, sempre e cada vez mais, ressalte-se a importância de um ator social cujo protagonismo deve tomar seu devido destaque na cena: os trabalhadores de saúde. Primeiro, para o alcance da verdadeira medida da complexidade, da abrangência e das interfaces de sua ação, o que inclui elementos que envolvem da sua formação à sua qualificação para agir em saúde. Segundo, para o dimensionamento do lugar e do papel que verdadeiramente ocupa na agenda da gestão do sistema de saúde. E, terceiro, para a constatação da centralidade que ocupa na questão da atenção à saúde, prestada no interior dos serviços do SUS em todos os níveis. E antes que a terceirização desenfreada e a desregulamentação das relaçóes de trabalho comprometam ainda mais o desempenho de um ator político, cujo tratamento, em geral, não conseguiu superar os limites burocráticos e as amarras do convencional, que insistem em continuar tratando a 
gestão do trabalho como questão centrada na administração de pessoal ou como desenvolvimento de pessoal e de recursos humanos.

Precisamos, pois, dar passos mais largos para a construção de uma relação ético-dialógica entre a gestão e o trabalho, de modo a incluir no conjunto de forças sociais envolvidas com a construção do SUS também os trabalhadores; sob uma perspectiva na qual sejam vistos como portadores de protagonismo e de capacidade de autogoverno, e não somente como força de trabalho submetida passivamente às injunções administrativas e gerenciais, ou subsumida nas questóes corporativoprofissionais que a regulamentam e despedaçam.

A fim de assegurar os compromissos social e político por parte dos gestores, na forma de decisão política no cumprimento dos preceitos legais para a implementação do SUS, resta por fazer um pacto com os trabalhadores em cada nível de governo. Com os recursos e instrumentos do planejamento em saúde, nas magnitude e abrangência necessárias, sem o revés das tentações centralizadoras e tendo como foco as realidades locais, tomando suas peculiaridades como espelho para o encaminhamento de soluçóes e respostas às demandas, um pacto entre a gestão e o trabalho gera enormes possibilidades para o caminho da implementação da política de saúde, que desde a criação do SUS persegue o encontro fecundo entre a intenção e o gesto, num sistema único, porém pleno de potencialidades do diverso e do múltiplo, e aberto aos desafios de um processo de construçáo que parece nunca acabar (ACIOLE, 2006).

A intenção deste artigo, elaborado a partir de reflexóes acumuladas na trajetória pessoal do autor (que foi, em momentos diversos, dirigente sindical, médico, participante de movimentos e projetos de reforma e transformação da formação em saúde, além de gestor municipal de saúde), é propor a efetivação de um pacto ético-político construído consensualmente entre os dois atores coletivos - gestores e trabalhadores da saúde -, colocando ambos no caminho da efetiva implantação do SUS. Pacto em que os primeiros possam oferecer não apenas remuneração justa, como também condiçóes infraestruturais de trabalho; que estas estejam atreladas ao alcance de objetivos postos na garantia da qualidade da assistência e do real atendimento às necessidades de saúde da população brasileira. Já os segundos, que possam ser levados a repensar sua inserção e seu papel, de modo que o empenho no alcance dos objetivos pactuados possa ser o motor para o atendimento de sua reivindicação por remuneração justa, concomitantemente com o engajamento substancial na mudança das condiçôes de saúde e doença da população assistida. Realizar esse pacto significa, portanto, trilhar passo importante na construção de uma correlação de forças favorável ao enfrentamento dos desafios éticos e políticos colocados na cena institucional brasileira desde o nascimento constitucional do SUS, em 1988.

\section{Uma proposta para a gestão do trabalho: construção do pacto ético-político entre gestores e trabalhadores}

Entendermos o modelo assistencial como o doador de sentido às ações da política de saúde, em geral, e da gestão do trabalho, em particular, implica a ampliação das discussóes para reformulação da prática acima apontada, a fim de que se articule uma política específica de gestão do trabalho dentro do SUS, em consonância com a conjuntura apontada. Em outras palavras, a gestâo do trabalho deve ser vista como um lugar de formulação e execução da política de saúde e de uma política para o trabalho no SUS. Uma execução ágil, eficaz e democrática de uma política construída por decisóes tomadas em colegiados paritariamente constituídos. Ao se voltar para a qualificação do processo de trabalho no campo da assistência e da gestão, esta área deve buscar atingir respostas efetivas aos três imperativos colocados anteriormente na introdução deste texto. A partir desse enfoque, podemos ressaltar como seu objeto que intermedeie um processo de aproximação entre a gestáo e o trabalho, de modo a transcender os aspectos formais do contrato, estabelecendo um diálogo entre estes dois coletivos e arrastando ambos para a efetiva implantação do Sistema Único de Saúde.

A construção desse consenso ético-político deve procurar âncora em diretrizes que balizem o desencadeamento do processo em todos os locais da organizaçáo ao mesmo tempo que permitam, revelem e respeitem as 
particularidades locais. Dos gestores, como já dissemos, que passem a oferecer tanto condiçôes infraestruturais e materiais de trabalho quanto uma remuneração mais justa e equânime com as reais necessidades e motivaçóes dos trabalhadores, atrelada, no todo ou em parte, ao alcance de objetivos pactuados prévia e continuamente. Dos trabalhadores, deseja-se que possam ser e estar envolvidos na adesão crítica e consciente ao projeto, e que repensem o seu papel, assumindo a dimensão de parceiros construtores desse projeto e náo somente de seus executores. Adesão crítica, na proporção em que o empenho no alcance das mesmas metas e objetivos possa ser o motor para o atendimento de suas reivindicaçóes por remuneração justa, mas que também signifique progressiva melhora das condiçôes infraestruturais desse desempenho e progressivo envolvimento, responsabilização e vínculo de si com a população sob cuidado.

Para tanto, destaquemos alguns princípios norteadores desse processo de pactuação: a) Considerar o setor público como espaço de investimento, portanto, merecedor de um olhar e de um agir políticos diferenciados, em busca de resultados que os legitimem perante o meio social; b) que a qualificação da assistência à saúde, prestada no interior do aparelho estatal, seja tomada como instrumento para essa legitimação; c) Em consequência dos anteriores, que o atendimento às necessidades da população assistida deva presidir todos os momentos do processo de trabalho localizado nos serviços e nas ações desenvolvidas; d) Nesse escopo, o resgate da dignidade do exercício profissional, em todas as suas instâncias, surge como condição necessária e inerente à consecução dos princípios anteriores.

Diante dessas questôes, o processo de construção do pacto entre gestores e trabalhadores deverá se desencadear em condiçôes, aqui destacadas somente para efeito de apresentação, mas que devem se realizar de modo simultâneo e complementar, a fim de bem ordenar a relação entre a gestão e o trabalho em saúde. Condiçôes que não devem ser compreendidas em uma dimensão semântica de aspectos conjunturais, mas que representam os necessários desdobramentos para que a pactuação pretendida aconteça de forma a subsumir o que parece ser um recorte assistencialista, com um efetivo engajamento da gestão e do trabalho em buscar a atençáo integral às necessidades de saúde da população brasileira em todos os níveis, ações e serviços do sistema de saúde.

Atender aos imperativos de construção de um pacto ético-dialógico entre gestores e trabalhadores, portanto, implica a ideia de que no interior dos espaços institucionais, seja dos serviços locais, seja das organizaçōes maiores como as secretarias de saúde, desencadeiem-se os seguintes momentos de um processo que representa o movimento de construção do pacto a ser efetivado. Esclareçamos, ademais, que utilizamos a palavra momento na sua acepção de potência de mover ou pôr em movimento, e não com o significado de hiato ou intervalo de tempo.

\section{Primeiro momento: a discussão do modelo assistencial}

Mais do que uma discussão dos méritos do modelo organizacional da assistência à saúde, em vigência no município ou nas redes regionais de atenção à saúde, o que pode significar, em última instância, a discussão ideologizada das concepçóes políticas do governo no aparelho do Estado, interessa aqui, para o momento deste passo, a explicitação dessa política em seus elementos analíticos: do que se compóe ou como se estrutura; para quem é voltada; e quais são seus objetivos e prioridades, de modo a explicitar o interesse público como o norte maior das políticas sociais.

Assim, é importante colocar em relevo e pôr em debate como se organiza; quais os critérios existentes para inclusão/exclusão; como se dá a participação popular para o controle social da gestão pública; quais são os principais aspectos do financiamento, da gestão financeira e das estruturas organizacional e administrativa, democratizando informaçóes e ampliando os canais de transparência e democracia institucional. Esse movimento de elucidação diagnóstica levará, necessariamente, à identificação dos 'interlocutores', de modo a estabelecer, de modo peremptório e cabal, a representação institucional e formal dos gestores e dos trabalhadores, bem como ao envolvimento direto daqueles que constituem seus antípodas institucionais - os 'usuários' 
- nas suas instâncias representativas e deliberativas - os conselhos gestores.

$\mathrm{Na}$ outra ponta da interlocução sistêmica do pacto com os trabalhadores, haveria que se dedicar tempo e atenção às dimensóes estruturais e financeiras do sistema de saúde. A caracterização dos recursos, suas origens e a interação entre os mesmos seriam dimensóes a serem trabalhadas, no sentido de revelar situaçôes e estruturas condicionantes/determinantes de resultados desejados/alcançados. Da mesma forma, isso deve ser feito com relação aos eixos balizadores do modelo. Assim, a organização da referência e da contrarreferência, por exemplo, explicitaria outro sem número de situações que produzem interações entre os diversos níveis da atenção. Isso leva, por sua vez, a que se apresente o modus operandi que define/condiciona/estrutura, ou não, a hierarquização de procedimentos: qual o seu grau de amplitude, qual o nível de sua organização, levando, ou não, à horizontalização dos profissionais. Finalmente, mas não por último, a adscrição de clientela, como importante denominador da equação: gestão-trabalhadores-usuários.

\section{Segundo momento: a discussão do processo de trabalho}

Para esta discussão, importa, sobretudo, 'discriminar positivamente o papel de cada corporação profissional no processo'; e ter em vista a compreensão crítica de algumas das variáveis que apontamos anteriormente. É preciso ressaltar as especificidades que cercam os procedimentos envolvidos: os saberes e práticas envolvidos, a organização de equipes, os mecanismos de planejamento, gestão e regulação, como pano de fundo a intermediar as relaçóes entre os atores envolvidos. Para esse passo, propomos a discussão e a análise 'da lógica/racionalidade do sistema ou da rede', no sentido de identificar se é aberta, burocratizadora, receptiva etc. Um estudo do processo de entrada e saída do paciente dentro do sistema, por exemplo, permite revelar como interagem e como se condicionam os momentos de acolhimento, diagnóstico, conduta e gerenciamento do cuidado para a obtenção deste ou daquele resultado. A 'apresentação das diferentes unidades de saúde e a composição das equipes/unidades' se constituem em uma etapa problematizadora das diferenças e especificidades, no sentido de garantir o tratamento de diferentes como desiguais e de evitar os vieses de uma sub ou superestimação do que é a moda, ou a média, incorrendo em uma dupla possibilidade de erro: ocultar as unidades/equipes problemáticas dentro do sistema e/ou puxar para baixo ou para cima os resultados da avaliação, mascarando seus verdadeiros objetivos. A 'discussão do papel, individual e coletivo, de cada corporação e de cada profissional, e do compromisso exigido' para o exercício desse papel é outra etapa de capital importância, especialmente se compreendida como momento de pactuação inter e intraequipes e grupo dirigente, e enquanto fase ou etapa produtora de corresponsabilidade recíproca, e não para afirmar/reafirmar poderes e lógicas estabelecidas.

\section{Terceiro momento: a discussão da gestão e sua organização}

Consideramos fundamental a discussão do 'papel da gestão, seus recursos e sua interação com os meios e instrumentos' que gerencia para estabelecer uma compreensão crítica de uma das pontas da equação - a gestão do sistema e do trabalho em saúde, de forma a ir além de sua dimensão administrativa. Ainda que também seja uma instância responsável por aspectos formais da relação de trabalho, a gerência deve ganhar, aqui, ou ter apontada entre suas características a condição de instrumento a serviço da produçáo de elos de integração e fomento do trabalho solidário, depositária de uma identidade profissional que procura subsumir todas as demais sem anular-lhes as especificidades. $\mathrm{O}$ 'modelo de gestão', igualmente, deve ter destacadas as suas características, tanto como condição estruturante para a gestão do trabalho, como instância delimitadora e estruturadora dos limites e das amarras do cotidiano da mesma, agregando subprodutos que se constituem em variáveis construtoras de itens da própria avaliação, ao mesmo tempo que produzem tessituras constitutivas da própria avaliação em si. Assim, por exemplo, se o modelo de gestão é colegiado ou não, centralizador ou 
não, no todo ou em parte, ou seja, se permite encontros periódicos das equipes; se os realiza; se propicia espaços de encontros entre os diversos níveis da gestáo e do trabalho; se existe conformação de equipes de trabalho em função de produtos esperados; se cada profissão faz a sua parte de acordo com a sua especialidade; se existe espaço de planejamento coletivo ou de discussáo de prioridades etc. As 'características problematizadoras' são decorrentes da discussão da etapa anterior, e serão definidas em função das características apontadas para o modelo de gestão em exame. Assim, um modelo centralizador, verticalizado, terá identificadas características que balizarão a sua transformação em modelo de gestáo colegiado, democrático e dialógico, e assim por diante.

\section{Quarto momento: a elaboração de instrumentos}

O passo seguinte, antes de esgotada a realização dos anteriores, será a 'definição das regras do jogo, de modo a permitir o feedback necessário para o acompanhamento e o aprimoramento do processo'. Fundamental para a objetivação do processo e para a posterior avaliação será a participação de todos os sujeitos envolvidos, em sua dupla perspectiva: de submetidos e de agentes ativos, como dimensóes que firmam explicitamente a compreensão do processo como uma construçấo coletiva e paritária e cujos interesses particulares se subsumem no objetivo transcendente de um salto qualitativo nas relaçóes entre a gestão e o trabalho. Os 'elementos singulares do processo deverão ser produtos dotados de natureza superior às meras voliçôes corporativas, engajamentos voluntaristas ou posiçóes militantes ou idiossincráticas. Assim, os instrumentos do pacto devem se pautar pelas transformaçóes na qualidade, pelos aspectos éticos de compromisso e pela adesão de equipes e de serviços, bem como por indicadores epidemiológicos e de resultados que meçam transformações na atenção às necessidades de saúde dos usuários', e não apenas pela produção de atos profissionais. São dimensôes necessárias ao processo de coletivização do pacto. Algumas 'ferramentas' serão estabelecidas em consequência dessa etapa. Assim, a caracterização da clientela, a composição e a habilidade das equipes de trabalho, os protocolos de atendimento específicos, os indicadores de saúde e outros, poderão ter sua construção ou utilização definidas, na medida em que o processo de pactuação estiver sendo executado.

\section{Quinto momento: desencadeamento do processo}

Um quinto e, talvez, decisivo passo subsume e dá o eixo organizacional e o sentido a todos os anteriores: desencadear a construção do pacto. Em consideraçáo à ideia de 'processo', este momento se dará desde que se inicie o primeiro passo. Importante apontar algumas sugestôes, a nosso ver, facilitadoras da tarefa, e que já vimos pespontando ao longo deste detalhamento. A primeira diz respeito à necessidade de sua construção coletiva. Assim, é recomendável a constituição de uma equipe que reúna elementos tanto do nível gerencial central como das áreas meios e dos serviços de assistência direta, não só para tornar mais rica e inteira a discussão, mas também para fazer do grupo uma estratégia de envolvimento de todos os atores na tarefa em si e para si. A segunda sugestão diz respeito à necessidade de que o processo adquira uma característica de organicidade, em que o coletivo das equipes de trabalho se sinta apropriado do processo todo, aqui compreendido enquanto propiciador de estímulo ao sentimento de corresponsabilidade. A terceira procura se referir ao cuidado de que nenhuma categoria profissional deva ter subestimado o seu potencial e o seu papel para a construção da assistência, ainda que o seu valor de uso social possa ser maior ou menor na perspectiva do senso comum. Finalmente, uma prévia avaliação das condições objetivas de governabilidade, dentro da convicção de que esse processo, uma vez desencadeado, deva ganhar caráter de irreversibilidade para garantir-lhes as condiçôes necessárias de existência e continuidade, consideradas suas potencialidades e seus atributos na direção das mudanças necessárias, tendo em vista o alcance dos objetivos e das metas gerais apontados no início deste trabalho. Para esse aspecto, convém considerarmos aspectos que estão presentes em arenas colegiadas, como 
a dos conselhos de saúde: é imprescindível a garantia de aspectos formais e legais, tanto quanto de representatividade e legitimidade dos atores que sentarão à mesa para a elaboração dos termos do pacto.

\section{Sexto momento: a avaliação do processo}

Em consonância com o que foi dito antes, é preciso constituir a avaliação como um instrumento para a gestão, colocando-a na perspectiva de dispositivo de análise, e inserida em um processo de vinculação entre objetivos e metas pactuados, o que significa o atendimento às necessidades da população assistida e uma resposta às demandas das categorias profissionais envolvidas no processo de produção da assistência à saúde. E também enquanto uma etapa de definição da política de valorização dos profissionais envolvidos nesse mesmo processo. Isso significa compreendê-la como um processo de negociação entre os atores envolvidos na intervenção a ser avaliada, ou seja, pressupóe a construção de um diálogo permanente entre interlocutores, em igualdade de situação discursiva, preocupados em constituir um espaço dialógico de natureza ética para que a avaliação se constitua não somente em uma leitura dos resultados, mas seja igualmente geradora de procedimentos e práticas de aprendizagem, pela identificação coletiva do que constituirá categorias e elementos de análise e acompanhamento (HARTZ; CONTRANDIOUPOLOS, 2008).

Para tanto, entendemos ser necessária a observância de algumas medidas preservadoras desse espírito ético-dialógico. A primeira é que a avaliação precisa ser doadora de sentido. E, nesse caso, um duplo sentido: tanto uma clara definição de 'para quê' e 'por quem' precisa ser feita, de 'como', 'quando' e 'onde' precisa que aconteça, quanto compreendida além da dimensão de auditagem mecânica e fria, ou acima da perspectiva de supervisão autoritária e rígida, ou, ainda, como uma espécie de intermediária entre o trabalho e a recompensa. $\mathrm{Ou}$, pior, como pacote gestado em instâncias superiores. Assim, tanto por quem a faz como por quem a recebe, o que aqui é mera separação didática, a avaliação deve tomar o desempenho em uma perspectiva de produto coletivo, que subsume, mais do que reúne, os diferentes desempenhos individuais. A segunda é que não pode provocar o desaparecimento do componente individual, porque submerso na equipe ou para evitar os nós críticos que a discriminaçâo positiva dos desiguais deve suscitar. Isso se torna possível na medida em que o trabalho em equipe deixe de ser uma abstração em termos e se constitua em processo de autonomia profissional e autogoverno, em que se considerem os interesses pessoais e os interesses grupais como fatores em si condicionantes. Portanto, para corresponder ao sentido anteriormente apontado, que se considere conditio sine qua non a sua construçáo coletiva.

A terceira decorre do fato de que, enquanto instrumento de uma relação ético-dialógica, esse momento do pacto não pode, isto é, a avaliação não pode, simplesmente, aparecer como por encanto no seio da organização. Não deve vir como encomenda! Que náo seja despencada como um pacote e/ou não venha como fator de produção pecuniária! Antes, e de novo, para que faça sentido, deve ser instaurada no interior de um processo de discussão coletiva que lhe infunda necessidade, inerente e intangível. Por conta mesmo do respeito ao sentido e à introjeção de seu significado, e de ser colocada sob a perspectiva de construtora de um contrato de gestão, sob a premissa de ser construída em processo.

Uma característica fundamental, consequência e razão para que se constituam as anteriores, reside na identificação e na construção coletiva dos objetivos colocados, dos critérios adotados e dos papéis em situação de avaliados, com toda a clareza possível por todos os envolvidos, de modo que não apenas se superem problemas oriundos dessa natureza, como também se possa lidar em maior grau e com maior tranquilidade diante do imediatismo dos resultados, positivos ou negativos, na direção de um contínuo e solidário repensar crítico das próprias funções da organização. Um processo, enfim, cuja viabilidade não se atrela exclusivamente à eficácia ou aos resultados, mas essencialmente aos passos dados na sua construção. E esse proceder também constitui escopo para a construção crítica do sujeito coletivo, na sua dupla dimensão de avaliador-avaliado. 


\section{Considerações Finais}

Ao apresentarmos a proposta aqui delineada, pretendemos contribuir para uma discussão que se faz cada vez mais necessária à medida que o processo de construção do SUS adentra em anos e continuamos imersos na perspectiva de um processo que se move em uma conjuntura (cultural, política e econômica) adversa de crises que se sucedem, sobre uma estrutura de complexidade e disparidade que parece intransponível, mas na qual não se pode desconsiderar, ou relativizar como fundo ideológico, a questão da ainda aguda desassistência que marginaliza expressivo contingente de brasileiros, na medida em que não logramos soluçóes efetivas e duradouras para pontos de estrangulamento do sistema de saúde.

Sem querer desconsiderar a importância tangível que têm esses elementos, ressaltamos a necessidade simultânea da construção de um diálogo permanente entre gestores e trabalhadores, como forma de constituir uma correlação de forças, inclusive institucionalizada, que permita acumular outras perspectivas na direção dos desafios colocados pela construção de um sistema de saúde universal e resolutivo, de reconhecimento do direito à saúde enquanto acesso concreto a serviços e açóes, inclusive pela construção de outro 'usuário' consciente desse direito e participativo nas decisóes e no controle, e que se constitua em instrumento de ampliação do potencial transformador da atenção à saúde, em suas dimensóes tanto quantitativas quanto qualitativas, almejando alcançar a efetiva integralidade do cuidado para a sociedade brasileira.

Mais do que uma receita, a ideia é de caminho, trilhado em margens muito seguras, para a pactuação entre gestores e trabalhadores, voltada tanto para uma melhora das relaçóes internas no seu processo de produção do cuidado à saúde quanto, por consequência, para uma mudança dos resultados obtidos, isto é, a qualificação da produção do cuidado em saúde em todos os níveis de atenção e em todos os serviços constituintes do sistema de saúde. Ambas as mudanças, melhora dos indicadores de assistência e de saúde da população, serão, enfim, os produtos deste pacto ético-dialógico aqui proposto.

Ao mergulharmos na construção desse pacto, daremos passo importante para a transformação da realidade sob intervenção, possibilitando a construção de outra imagem pública para o setor saúde, e ofereceremos alternativa crítica significativa perante o modelo neoliberal que nos quer modelar pelo mercado, ou mesmo reduzir a velocidade do avanço das políticas e mecanismos que póem sob permanente ameaça a garantia prática dos direitos sociais, entre os quais se insere o direito à saúde, mesmo com a ressalva de que os pactos - sejam eles quais forem - não portam consigo a capacidade de serem soluçôes simples para uma tarefa complexa e polimorfa.

\section{Referências}

ACIOLE, G. G. Redes interfederativas de saúde: um arranjo assistencial instituinte ou mais uma estratégia gerencial? Ciência \& Saúde Coletiva, Rio de Janeiro, v. 16, n. 3, p. 1681-87, mar. 2011.

A Saúde no Brasil: cartografias do público e do privado. São Paulo: Hucitec; Campinas: Sindimed, 2006. 357p.

ALMEIDA FILHO, N. A problemática teórica da determinação social da saúde (nota breve sobre desigualdades em saúde como objeto de conhecimento). Saúde em Debate, Rio de Janeiro, v. 33, n. 83, p. 349-370, set./dez 2010.

BRASIL. Ministério da Saúde. Ministério do Planejamento, Orçamento e Gestão. Fundação Estatal: metas, gestão profissional e direitos preservados. Brasília: Ministério da Saúde, 2007. 16 p. (Série C. Projetos, Programas e Relatórios).

Ministério da Saúde. Secretaria Executiva. Diretrizes operacionais para os pactos de vida, em defesa do SUS e de gestão. Brasília: Editora do Ministério da Saúde, 2006. 70p.

CECCIN, R.; FEUERWERKER, L. M. O quadrilátero da formação para a área da saúde: ensino, gestão, atenção e controle social. Physis: Revista de Saúde Coletiva, Rio de Janeiro, v. 14, n. 1, p. 41-65, jan./ fev. 2004a.

Mudança na graduação das profissões de saúde sob o eixo da integralidade. Cadernos de Saúde Pública, Rio de Janeiro, v. 20, n. 5, p. 1400-1410, maio 2004b. 
DAIN, S. et al. Avaliação dos impactos de reforma tributária sobre o financiamento da Saúde. In: NEGRI, B.; Di GIOVANNI, G. (orgs.). Brasil: radiografia da Saúde. Campinas: Instituto de Economia, 2001. p. 233-288

FLEURY, S.; LOBATO, L. V. C. (orgs.). Seguridade social, cidadania e saúde. Rio de Janeiro: CEBES, 2009. 204p.

GUERREIRO, J. V.; BLANCO, M. A. F. Dos pactos políticos à política de pactos na saúde. Ciência \& Saúde Coletiva, Rio de Janeiro, v. 16, n. 3, p. 1689-1698, mar. 2011.

HARTZ, Z.; CONTRANDIOPOULOS, A. P. Do quê ao pra quê da metaavaliação em saúde. In: HARTZ, Z.; FELISBERTO, E.; SILVA, L. M. V. (Orgs.). Meta-Avaliação da Atenção Básica à Saúde: teoria e prática. Rio de Janeiro: Editora FIOCRUZ, 2008. p. 27-45.

LEVCOVITZ, E.; LIMA, L. D.; MACHADO, C. V. Política de saúde nos anos 90: relações intergovernamentais e o papel das normas operacionais básicas. Ciência \& Saúde Coletiva, Rio de Janeiro, v. 6, n. 2, p. 269- 291, 2001.
MERHY, E.E. Organizações sociais. Para que? In: DEBATE 'Organizações sociais: Público e privado na Saúde'. São Paulo: APSP, 1999. p. 19-48.

SANTOS, L.; ANDRADE, L. O. M. A organização do SUS sob o ponto de vista constitucional: rede regionalizada e hierarquizada de serviços de saúde. In: SILVA, S. F. (org.) Redes de atenção à saúde no SUS. Campinas: IDISA, 2008a. p. 23-34.

Rede interfederativa de saúde. In: SILVA, S. F. (org.). Redes de atenção à saúde no SUS. Campinas: IDISA, 2008b. p. 35-65.

SILVA, S. F.; MAGALHÃES JUNIOR, H. M. Redes de atenção á saúde: importância e conceitos. In: SILVA, S. F. (org.) Redes de atenção à saúde no SUS. Campinas: IDISA, 2008. p. 69-86.

SILVA, G. G. A.; EGYDIO, M. V. R. M.; SOUZA, M. C. Algumas questões sobre o controle social no SUS: usuários ou consumidores? Saúde em Debate, Rio de Janeiro, v. 15, n. 53, p. 36-39, jan./abr. 1999.

Recebido para publicação em Maio/2011

Versão definitiva em Junho/2012

Suporte financeiro: não houve

Conflito de interesse: inexistente 